\title{
Covid-19 Sürecinde Gebelerde Görülen Ruh Sağlığı Sorunları ve Sosyal Destek Algısı
}

\author{
Mental Health Problems and Perception of Social \\ Support in Pregnant Women in the Covid-19 Process
}

\author{
Mevlüde ALPASLAN ARAR ${ }^{1}$, Fatma YILDIRIM², Ebru ŞAHIN³ \\ 1 Ordu Üniversitesi Sağlık Bilimleri Enstitüsü, Doğum ve Kadın Hastalıkları Hemşireliği Anabilim Dalı \\ - mevlude_alpaslan@hotmail.com • ORCID > 0000-0002-8586-2800 \\ ${ }^{2}$ Hitit Üniversitesi Sağlık Bilimleri Fakültesi, Doğum ve Kadın Hastalıkları Hemşireliği Anabilim Dalı \\ - fatmadmryldrm@gmail.com•ORCID > 0000-0002-1996-4278 \\ ${ }^{3}$ Ordu Üniversitesi Sağlık Bilimleri Fakültesi, Doğum ve Kadın Hastalıkları Hemşireliği Anabilim Dalı \\ •ebrugabalci_@hotmail.com• ORCiD > 0000-0001-7798-0690
}

Makale Bilgisi / Article Information

Makale Türü / Article Types: Derleme / Review

Geliş Tarihi / Received: 14 Haziran / June 2021

Kabul Tarihi / Accepted: 10 Kasım / November 2021

Yıl/Year: 2021 | Cilt - Volume: 6 | Sayı - Issue: Özel Sayı 1 | Sayfa / Pages: 1-9

Atıf/Cite as: Alpaslan Arar, M., Yıldırım, F. ve Şahin, E. "Covid-19 Sürecinde Gebelerde Görülen Ruh Sağlığı Sorunları ve Sosyal Destek Algısı - Mental Health Problems and Perception of Social Support in Pregnant Women in the Covid-19 Process". Samsun Sağlık Bilimleri Dergisi - Journal of Samsun Health Sciences, 6(Ö.1), Aralık 2021: 1-9. https://doi.org/10.47115/jshs.951659

Yazar Notu: Bu derleme çalışması, Ondokuz Mayıs Üniversitesi Hemşirelik Bölümü’nün 26-28 Mayıs 2021 tarihinde düzenlediği IV. Hemşireliği Güçclendirme Sempozyumu’nda sözel bildiri olarak sunulmuştur.

Sorumlu Yazar: Mevlüde ALPASLAN ARAR

Copyright @ Published by Ondokuz Mayıs Üniversitesi, Sağlık Bilimleri Fakültesi - Ondokuz Mayıs University, Faculty of Health Sciences, Samsun, Turkey. All rights reserved. 


\section{COVID-19 SÜRECINDE GEBELERDE GÖRÜLEN RUH SAĞLIĞI SORUNLARI VE SOSYAL DESTEK ALGISI}

\section{ÖZ:}

Gebelik genellikle olumlu duygularla ilişkilendirilen bir yaşam olayıdır. Ancak, bu süreç bazı kadınların kolayca adapte olamadığı fiziksel, psikolojik ve sosyal değişiklikleri içermesi nedeniyle stresli bir yaşam olayı olarak deneyimlenebilmektedir. Ruhsal sorunların arttığı bir dönem olan gebelik sırasında gebelerin tıbbi komplikasyonlar, doğal afetler ve hastalık salgınları gibi durumlara maruz kalmaları ruh sağlığı sorunlarını artırabilmektedir. Aralık 2019'dan bu yana yeni koronavirüs hastalığının (COVID-19) ortaya çıkması ile yıkıcı bir küresel sağlık krizi yaşanmaktadır. Bu viral enfeksiyonla ilişkili artan morbidite ve mortalite oranlarını ve COVID-19'un yayılmasını önlemek için alınan sosyal ve fiziksel önlemler, kişilerin sosyal bağlantılarına ve günlük hayatın normal rutinlerine ciddi kesintiler getirmiştir. Yaşamsal kriz dönemlerinden biri olan gebelik sürecinde görülen bu sosyal destek kesintileri, bireyin stres faktörünün artmasında rol oynamaktadır. Sosyal destek salgın hastalıklar ve doğal afetlerden kaynaklanan olumsuz ruh sağl1ğ1 zorluklarına karşı koruyucu bir faktör olarak hareket etmektedir. Sosyal desteğin bilişsel değerlendirme, tutum ve algılanan stresin refah üzerindeki etkisini hafiflettiğine dair kanıtlar da vardır. Bir taraftan gebeliğin verdiği sorumluluk ve kadının bu rollere ilişkin ruhsal uyumu, diğer taraftan da COVID-19'un fetüs üzerindeki etkilerine ilişkin verilerin yetersiz olması, doğumun nasıl gerçekleşeceği gibi soru işaretleri gebelerde kaygı ve ruhsal bozukluklara yol açabilmektedir. Gebelerin yaşadığı kaygı ve ruh sağlığı sorunlarında sosyal destek mekanizmalarının önem arz ettiği ve gebelerin hemşire/ebe takibine ihtiyaç duyduğu bildirilmiştir. Bu derlemede, COVID-19 salgını sürecinde gebelikte karşılaşılan ruh sağlığı sorunları, buna yönelik sosyal desteğin önemi ve hemşirelik yaklaşımı ele alınacaktır.

Anahtar Kelimeler: Covid-19; Gebelik; Ruh sağlı̆̆l; Sosyal destek; Hemşirelik

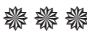 \\ MENTAL HEALTH PROBLEMS AND PERCEPTION OF SOCIAL SUPPORT IN PREGNANT WOMEN IN THE COVID-19 PROCESS}

\section{ABSTRACT:}

Pregnancy is a life event often associated with positive emotions. However, this process can be experienced as a stressful life event because it involves physical, psychological and social changes that some women cannot easily adapt to. Exposure of pregnant women to situations such as medical complications, natural disasters 
and disease outbreaks during pregnancy, which is a period when mental problems increase, can increase mental health problems. Since December 2019, there has been a devastating global health crisis with the emergence of the novel coronavirus disease (COVID-19). The increasing morbidity and mortality rates associated with this viral infection and the social and physical measures taken to prevent the spread of COVID-19 have brought serious disruptions to people's social connections and normal routines of daily life. These social support interruptions during pregnancy, which is one of the vital crisis periods, play a role in increasing the stress factor of the individual. Social support acts as a protective factor against negative mental health challenges resulting from epidemics and natural disasters. There is also evidence that social support moderates the impact of cognitive appraisal, attitude, and perceived stress on well-being. On the one hand, the responsibility of pregnancy and the mental adaptation of the woman to these roles, on the other hand, the insufficient data on the effects of COVID-19 on the fetus and question marks such as how the birth will take place can cause anxiety and mental disorders in pregnant women. It has been reported that social support mechanisms are important in anxiety and mental health problems experienced by pregnant women and that pregnant women need nurse/midwife follow-up. In this review, mental health problems encountered during pregnancy during the COVID-19 epidemic, the importance of social support and nursing approach will be discussed.

Keywords: Covid-19; Pregnancy; Mental health; Social support; Nursing

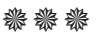

$$
\begin{aligned}
& \text { GİRiş }
\end{aligned}
$$

31 Aralık 2019'da Çin'in Wuhan kentinde tespit edilen ve nedeni bilinmeyen pnömoni vakası Dünya Sağlık Örgütü (DSÖ) Ülke Ofisine bildirilmiştir. Şubat 2020'de DSÖ bu yeni koronovirüs hastalığının ismini COVİD-19 olarak açılamıştı (WHO, 2020). Hızla tırmanış gösteren bu hastalık Uluslararası Halk Sağlığı Acil Durumu haline gelmişti (Wu ve McGoogan, 2020). Bu süreçte uluslararası obstetrik kuruluşlar ile doğum uzmanları bu hastalığın gebeler ve bebekler üzerinde nasıl bir etki oluşturabileceğini belirlemeye çalışmışlardı (ACOG, 2020).

Aralık 2019'dan bu yana yeni koronavirüs hastalığının ortaya çıkması ile yıkıcı bir küresel sağlık krizi yaşanmaktadır. Diğer taraftan şu anda tüm dünyayı etkileyen bu salgınının etkilerinin öngörülebilir bir gelecekte de devam etmesi beklenmektedir (Rees et al.,, 2019). Bir taraftan gebeliğin verdiği sorumluluk ve kadının bu rollere ilişkin ruhsal uyumu, diğer taraftan da COVID-19'un fetüs üzerindeki etkilerine ilişkin verilerin yetersiz olması, doğumun nasıl gerçekleşeceği gibi belirsizlikler gebelerde kaygı ve ruhsal bozukluklara yol açabilmektedir (Şimşek et al.,, 
2019). Gebelerin yaşadığı kaygı ve ruh sağlığı sorunlarında sosyal destek mekanizmalarının önemli olduğu COVID-19 pandemisi sürecinde, klinik yönetimin yanı sıra gebelerin psikolojik ve sosyal desteğe de ihtiyaçları olduğu bildirilmiştir (Khan et al.,, 2020; Khoury et al.,, 2021).

Bu derlemede, COVID-19 salgını sürecinde gebelikte karşılaşılan ruh sağlığı sorunları, buna yönelik sosyal desteğin önemi ve hemşirelik yaklaşımı ele alınacaktır.

\section{Gebelik ve COVID-19 Enfeksiyon Süreci}

Gebelik ile birlikte ortaya çıkan fiziksel ve hormonal değişikler gebe kadınları solunum yolu hastalıklarına daha yatkın hale getirebilmektedir. Gebe kadınlar, Şiddetli Akut Solunum Sendromu (SARS) ve Orta Doğu Solunum Sendromu (MERS) dahil olmak üzere diğer koronavirüslerle enfeksiyondan kaynaklanan komplikasyon ve ciddi hastalık yaşama riski daha yüksek olan, savunmasız bir grup olarak belirlenmiştir. Ayrıca gebe kadınların COVID-19 salgını sürecinde ek önlemler almaları önerilmiştir (Dashraath et al., 2019).

Pandeminin başlangıcından bu yana, gebe kadınların genel nüfusa kıyasla anne ölüm ve hastalık riskinin daha yüksek olduğu iddia edilmiştir (WAPM,2020; Di Mascio et al., 2020). Diğer taraftan COVID-19 ile gebelik sonuçları arasındaki ilişkinin doğası hala belirsizliğini korumaktadır (Huntley et al., 2020). 2020'de yayınlanan bir sistematik inceleme bulgularında gebe olan kişilerin SARS-CoV-2 enfeksiyonu veya semptomatik COVID-19 riskinde artış olmadığı, ancak gebe olmayanlara kıyasla ciddi COVID-19 enfeksiyonu riski altında oldukları bildirilmiştir (Allotey et al., 2020). Gebelik sırasında SARS-CoV-2 enfeksiyonu hakkında yayınlanan çok sayıda rapora rağmen, hem maternal hem de fetal olumsuz sonuç riskini artırabileceğini belirlemek için sadece birkaç çalışma yapılmıştır. $\mathrm{Bu}$ çalışmalardan bir tanesi de, SARS-CoV-2 enfeksiyonu için pozitif test edilen çok uluslu bir gebe kadın kohortunda yüksek riskli gebeliklerin olumsuz maternal ve perinatal sonuçlar açısından daha yüksek risk altında olup olmadığını araştırmayı amaçlayan D'Antonio ve arkadaşlarının (2021) gerçekleştirdiği çalışmadır. Bu çalışmada, SARS-CoV-2 enfeksiyonu ile komplike olan yüksek riskli gebelikler, düşük riskli gebeliklere kıyasla, çoğunlukla solunumla ilgili olmak üzere olumsuz sonuçlar açısından daha yüksek risk altında olduğu bulunmuştur. Gebelikte şiddetli akut solunum sendromu koronavirüs 2 enfeksiyonu ile olumsuz gebelik sonuçları arasındaki ilişkiyi değerlendirmeyi amaçlayan bir sistematik inceleme bulgularında ise, gebelikte COVID-19 enfeksiyonunun preeklemsi ve erken doğum ile ilişkili olduğu ve şiddetli COVID-19 enfeksiyonunun önemli ölçüde maternal ve neonatal morbiditeye yol açabileceği bildirilmiştir (Wei et al., 2021). Bu bulguları daha fazla doğrulamak, daha sağlam veriler toplamak, bu ilişkileri açıklayan patofizyolojik 
yolları daha iyi anlamak ve COVID-19 enfeksiyonu olan gebe kişilerde olumsuz sonuçları önlemek için daha fazla çalışmalara ihtiyaç vardır.

\section{COVID-19 Enfeksiyonu Sürecinde Gebelik ve Ruh Sağlığı}

Gebelik genellikle olumlu duygularla ilişkilendirilen bir yaşam olayıdır. Ancak, bu süreç bazı kadınların kolayca adapte olamadığı fiziksel, psikolojik ve sosyal değişiklikleri içermesi nedeniyle stresli bir yaşam olayı olarak deneyimlenebilmektedir (Rees et al., 2019; RCOG, 2020). Buna ek olarak gebenin ruh sağlığını etkileyebilecek tıbbi komplikasyonlara, doğal afetlere ve hastalık salgınlarına maruz kalma durumları; hali hazırda ruhsal sorunların arttığı bir dönem olan gebelik sırasında ruh sağlı̆̆ını ek olarak etkilemektedir (Rees et al., 2019). Covid-19 salgını sürecinde karşılaşılan; sağlık hizmetlerine ulaşımda gelen kısıtlamalar, antenatal bakım almada yaşanan sorunlar, virüsten kaynaklı gelişen hastalık durumları, alınan tedbirlere bağlı ortaya çıkan maddi zorluklar ve sosyal izolasyona bağlı aile-arkadaş desteğinin azalması gibi durumlar gebe kadınlarda kaygı ve anksiyete semptomları oluşturmaktadır (RCOG,2020). COVID-19 enfeksiyon salgınının hemen ardından Çin, İtalya ve Yunanistan'da yapılan araştırmalar, genel nüfusun yüksek depresyon, anksiyete ve uykusuzluk semptomları yaşadığını göstermektedir (Huang \& Zhao, 2020; Moccia et al., 2020; Voitsidis et al., 2020). Nisan 2020'de Kanada'da gebe kadınlar ile yapılan bir çalışmada, gebe bireylerin sırasıyla \%37 ve \%57'sinin klinik olarak yüksek depresyon ve anksiyete semptomları desteklediği bildirilmiştir (Lebel et al., 2020). Ayrıca, Amerika Birleşik Devletleri'nde Mayıs ve Ağustos ayları arasında gerçekleştirilen perinatal dönemdeki kadınlar ile yapılan bir araştırmada, \%36'sının yüksek düzeyde depresyon görüldüğü ve \%23'ünün endişeli olduğu bildirilmiştir (Liu et al., 2020). Bu bulgular, gebe kadınların pandeminin hemen ardından ve pandeminin ilk aşamasından sonra yüksek depresyon ve anksiyete yaşadıklarını göstermektedir. Gebelikte depresyon, anksiyete ve stres yaşanması, uzun dönemde maternal ve fetal sağlık problemlerine neden olabilmektedir (Allison, Stafford ve Anumba, 2011). Ruhsal sorunların, özellikle endişe ve depresyonun; gebelik komplikasyonlarını artırdığı, fetal sağlığı olumsuz etkilediği, düşük doğum ağırlığına, erken doğuma ve intrauterin gelişim geriliğine sebebiyet verdiği bildirilmektedir (Altın, 2012; Eskici ve ark, 2012). Bu nedenle, gebeler ve doğmamış çocukları için ikincil sağlı sorunlarının ortaya çıkmasını önlemeye ve COVID-19 pandemisinin gebe bireyleri nasıl etkilediğini anlamaya acilen ihtiyaç vardır.

\section{COVID-19 Enfeksiyon Sürecinde Gebelik ve Sosyal Destek}

Gebeler her türlü viral enfeksiyondan diğer popülasyona oranla daha fazla etkilenmektedir (Özcan et al., 2020). Virüsün gebelik sürecini ve fetusü ne derece etkilediği hakkındaki kanıt eksikliği ruhsal sağlığın bozulmasına neden olmaktadır (Brik et al., 2021). 
Bu viral enfeksiyonla ilişkili artan morbidite ve mortalite oranlarını ve COVID19'un yayılmasını önlemek için alınan sosyal ve fiziksel önlemler, kişilerin sosyal bağlantılarına ve günlük hayatın normal rutinlerine ciddi kesintiler getirmiştir. Yaşamsal kriz dönemlerinden biri olan gebelik sürecinde görülen bu sosyal destek kesintileri, bireyin stres faktörünün artmasında rol oynamaktadır (Khoury et al., 2021). Sosyal destek, salgın hastalıklar ve doğal afetlerden kaynaklanan olumsuz ruh sağlığı zorluklarına karşı koruyucu bir faktör olarak hareket etmektedir. Sosyal desteğin bilişsel değerlendirme, tutum ve algılanan stresin refah üzerindeki etkisini hafiflettiğine dair kanıtlar da vardır (Nnadozie \& Nweke, 2017; Şimşek et al., 2019). Sosyal desteğin, bireylerin depresyon, stres ve kaygıyı azaltmaya yardımcı olabilecek olumlu etkileşimleri olduğu ve dolayısıyla olumsuz gebelik ve doğum sonuçları riskini azalttığı düşünülmektedir. Sosyal destek, hamile kadınların stresli olaylarla başa çıkmaları için ek bir uygun başa çıkma mekanizması da sağlayabilir (Dunkel Schetter, 2011). Bu bağlamda hemşireler gebe kadınlarla aldıkları sosyal desteğin düzeyi ve kaynağı hakkında görüşmeli ve düşük sosyal desteğe sahip olduğu düşünülen gebelerin ruh sağlığı durumlarını izlemelidir (Bedaso et al., 2021).

Bu viral enfeksiyonla ilişkili artan morbidite ve mortalite oranlarını ve COVID19'un yayılmasını önlemek için alınan sosyal ve fiziksel önlemler, kişilerin sosyal bağlantılarına ve günlük hayatın normal rutinlerine ciddi kesintiler getirmiştir. Yaşamsal kriz dönemlerinden biri olan gebelik sürecinde görülen bu sosyal destek kesintileri, bireyin stres faktörünün artmasında rol oynamaktadır (Khoury et al., 2021). Sosyal destek, salgın hastalıklar ve doğal afetlerden kaynaklanan olumsuz ruh sağlığı zorluklarına karşı koruyucu bir faktör olarak hareket etmektedir. Sosyal desteğin bilişsel değerlendirme, tutum ve algılanan stresin refah üzerindeki etkisini hafiflettiğine dair kanıtlar da vardır (Nnadozie \& Nweke, 2017; Şimşek et al., 2019). Sosyal desteğin, bireylerin depresyon, stres ve kaygıyı azaltmaya yardımcı olabilecek olumlu etkileşimleri olduğu ve dolayısıyla olumsuz gebelik ve doğum sonuçları riskini azalttığı düşünülmektedir. Sosyal destek, hamile kadınların stresli olaylarla başa çıkmaları için ek bir uygun başa çıkma mekanizması da sağlayabilir (Dunkel Schetter, 2011). Bu bağlamda hemşireler gebe kadınlarla aldıkları sosyal desteğin düzeyi ve kaynağ 1 hakkında görüşmeli ve düşük sosyal desteğe sahip olduğu düşünülen gebelerin ruh sağlığı durumlarını izlemelidir (Bedaso et al., 2021).

\section{Covid-19 Enfeksiyonu Sürecinde Gebelerde Görüilen Ruh Sağlığı Sorunları ve Sosyal Destek Algısına Yönelik Hemşirelik Yaklaşımları}

Gebelerin yaşadığı kaygı ve ruh sağlı̆̆1 sorunlarında sosyal destek mekanizmalarına ve gebelerin hemşire/ebe takibine ihtiyaç duyduğu bildirilmiştir. Bu süreçte hemşireler (Rasmussen et al.,, 2020; Aydın et al.,, 2021); 
- Hastalık Kontrol ve Korunma Merkezi (CDC) enfeksiyon önlemlerini ve prosedürlerini uygulamalıdır.

- COVID-19 enfeksiyonu olan gebelere yönelik gerekli izolasyon önlemlerinin alınmasını sağlayarak hızlı bir şekilde triyaj yapmalıdır.

- Gebelik izlemlerinde kadının endișelerini, depresyon, anksiyete ve stres gibi ruh sağlığı sorunlarını belirlemeli ve kişiye özgü bakım sunmalıdır.

- Bulaş riski ve hızının yüksek olduğu COVID-19 salgınında, annelere fiziki sosyal desteğin azalacağ düşünülerek, annelerin bu sürece uyum sağlaması açısından eğitim ve danışmanlık hizmetleri ve olağandışı durumlarda annelerin destek sistemini geliştirecek önlemler almalıdır.

- Gebelerin sağlığı ve ruh sağlığı konularını kapsayacak biçimde eğitimler düzenlemelidir. Bu bağlamda ise annelere telefonla destek ya da çevrimiçi eğitim veya danışmanlık platformları oluşturmalıdır.

\section{SONUÇ}

Sonuç olarak, SARS-CoV 2 salgınının, gebe kadınlar arasında anksiyete ve depresyon semptomlarını artırdığı ve özellikle de daha az sosyal desteğe sahip olan gebe kadınları etkilediği bilinmektedir. Gebelerin yaşadığı kaygı ve ruh sağlığı sorunlarında sosyal destek mekanizmalarının önem arz ettiği bu süreçte, hemşireler bir sağlık profesyoneli olarak gebelerin sağlık hizmetlerinden eşit yararlanmasında ve tüm karmaşık bilgilerin anlaşılır hale getirilmesinde destekleyici bakım sağlamalıdir.

\section{Teşekkür ve Açıklamalar}

Dergi inceleme sürecinde katkı sunan hakemler ve editöre teşekkür ederiz.

\section{Çıkar Çatışması}

$\mathrm{Bu}$ çalışma ile ilgili olarak yazarların ve/veya aile bireylerinin çıkar çatışması potansiyeli olabilecek bilimsel ve tıbbi komite üyeliği veya üyeleri ile ilişkisi, danışmanlık, bilirkişilik, her-hangi bir firmada çalışma durumu, hissedarlık ve benzer durumları yoktur.

\section{Yazar Katkısı}

1. Fikir/Kavram: Mevlüde ALPASLAN ARAR, Fatma YILDIRIM 2. Tasarım: 


\section{Mevlüde ALPASLAN ARAR, Fatma YILDIRIM 3. Analiz ve/veya Yorum: Ebru ŞAHİN 4. Literatür Taraması: Mevlüde ALPASLAN ARAR, Fatma YILDIRIM 5. Makale Yazımı: Mevlüde ALPASLAN ARAR, Fatma YILDIRIM, Ebru ŞAHIN 6.}

\section{KAYNAKLAR}

ACOG. Outpatient assessment and management for pregnant women with suspected or confirmed novel coronavirus (COVID-19). (2020). Erişim tarihi: 01.05.2021, Erişim Adresi: https://www.acog.org/-/media/ project/acog/acogorg/files/pdfs/clinical-guidance/practice-advisory/covid-19 algorithm.pdf.

Allison, S., Stafford, J., \& Anumba, D. (2011). The effect of stres and anxiety associated with maternal prenatal diagnosis on feto-maternal attachment. BMC Women's Health, 11, 33.

Allotey, J., Stallings, E., \& Bonet, M., (2020). Clinical manifestations, risk factors, and maternal and perinatal outcomes of coronavirus disease 2019 in pregnancy: living systematic review and meta-analysis. BMJ , 370:m3320.

Altın, E.G. (2012). Perinatal depresyon tedavisinde kişilerarası terapi. Psikiyatride Güncel Yaklaşımlar-Current Approaches in Psychiatry, 4(2), 188-203.

Aydın, R., Kızılkaya, T., Aytaç, S. H., \& Taşlar, N. (2020). COVıD-19 Pandemisinde; Gebelik, Doğum ve Doğum Sonu Dönemde Kadınların Sosyal Destek Gereksinimi ve Ebelik Yaklaşımları. Electronic Turkish Studies, 15(4).

Bedaso, A., Adams, J., Peng, W., \& Sibbritt, D. (2021). The relationship between social support and mental health problems during pregnancy: a systematic review and meta-analysis. Reproductive health, 18(1), 1-23.

Brik, M., Sandonis, M. A., Fernández, S., Suy, A., Parramon Puig, G., Maiz, N., ... \& Carreras, E. (2021). Psychological impact and social support in pregnant women during lockdown due to SARS CoV2 pandemic: A cohort study. Acta Obstetricia et Gynecologica Scandinavica.

D'Antonio, F., Sen, C., Di Mascio, D., Galindo, A., Villalain, C., Herraiz, I., ... \& the behalf of the World, O. (2021). Maternal and perinatal outcomes in high compared to low risk pregnancies complicated by severe acute respiratory syndrome coronavirus 2 infection (phase 2): the World Association of Perinatal Medicine working group on coronavirus disease 2019. American Journal of Obstetrics \& Gynecology MFM, 3(4), 100329.

Dashraath, P., Wong, J.L.J., \& Lim, M.X.K., (2020). Coronavirus disease 2019 (COVID-19) pandemic and pregnancy. Am J Obstet Gynecol, 222,521-31.

Di Mascio, D., Sen, C., \& Saccone, G., (2020). Risk factors associated with adverse fetal outcomes in pregnancies affected by coronavirus disease 2019 (COVID-19): a secondary analysis of the WAPM study on COVID-19. J Perinat Med, 48, 950-8.

Dunkel Schetter, C. (2011). Psychological science on pregnancy: stress processes, biopsychosocial models, and emerging research issues. Annual review of psychology, 62, 531-558. Erişim Adresi: https://www.who.int/ emergencies/diseases/novel-coronavirus-2019/events-as-they-happen.

Eskici, L., Demir Akca, A.S., Atasoy, N., Arıkan, l., \& Harma, M. (2012). Gebelerde depresyon ve anksiyete bozukluğunun obstetrik sonuçları ve yenidoğan üzerine etkileri. Anatol J Clin Investig., 6(1), 10-16. https://www.acog.org/-/ media/project/acog/acogorg/files/pdfs/clinical-guidance/practice-advisory/covid-19 algorithm.pdf.

Huang, Y., \& Zhao, N., (2020). Generalized anxiety disorder, depressive symptoms and sleep quality during COVID-19 outbreak in China: a web-based cross-sectional survey. Psychiatry Res., 112954

Huntley, BJF., Huntley, ES., \& Di Mascio, D., (2020). Rates of maternal and perinatal mortality and vertical transmission in pregnancies complicated by severe acute respiratory syndrome coronavirus 2 (SARS-CoV-2) infection: a systematic review. Obstet Gynecol 2020;136:303-12

Khan, S., Peng, L., Siddique, R., Nabi, G., Xue, M., Liu, J., \& Han, G. (2020). Impact of COVID-19 infection on pregnancy outcomes and the risk of maternal-to-neonatal intrapartum transmission of COVID-19 during natural birth. Infection Control \& Hospital Epidemiology, 41(6), 748-750.

Khoury, J. E., Atkinson, L., Bennett, T., Jack, S. M., \& Gonzalez, A. (2021). COVID-19 and mental health during pregnancy: The importance of cognitive appraisal and social support. Journal of affective disorders, 282, 1161-1169.

Moccia, L., Janiri, D., Pepe, M., Dattoli, L., Molinaro, M., De Martin, V., \& Di Nicola, M. (2020). Affective temperament, attachment style, and the psychological impact of the COVID-19 outbreak: an early report on the Italian general population. Brain Behav. Immunity. 
Nnadozie, J. C., \& Nweke, G. E. (2017). Self esteem, social support and postpartum depressıon. Journal Of International Social Research, 10(51), 552-56.

RCOG. Coronavirus (COVID-19) infection in pregnancy. 2020.

Rees, S., Channon, S., \& Waters, C.S., (2019). The impact of maternal prenatal and postnatal anxiety on children's emotional problems: a systematic review. Eur. Child Adolesc. Psychiatry 28, 257-280.

Şimşek, H. N., Demirci, H., \& Bolsoy, N. (2018). Sosyal destek sistemleri ve ebelik. Düzce Üniversitesi Sağlkk Bilimleri Enstitüsü Dergisi, 8(2), 97-103.

WAPM (World Association of Perinatal Medicine) Working Group on COVID-19 (2020). Maternal and perinatal outcomes of pregnant women with SARS-COV-2 infection. Ultrasound Obstet Gynecol, 57, 232-41. 6.

Wei, S. Q., Bilodeau-Bertrand, M., Liu, S., \& Auger, N. (2021). The impact of COVID-19 on pregnancy outcomes: a systematic review and meta-analysis. CMA), 193(16), E540-E548.

WHO. Rolling updates on coronavirus disease (COVID-19). (2020). Erişim tarihi: 01.05.2021,

Wu, Z., \& McGoogan, J.M. (2020). Characteristics of and important lessons from the coronavirus disease 2019 (COVID-19) outbreak in China: summary of a report of 72314 cases from the Chinese Center for Disease Control and Prevention. Journal of American Medical Assosication, 323(13), 1239-1242. 